\section{Unemployment Insurance Claims and Economic Activity}

\author{
William T. Gavin and Kevin L. Kliesen
}

$\triangle 1$ lthough the Federal Open Market Committee (FOMC) monitors a large number of economic series when deciding whether to alter the current stance of its policy, it is generally accepted that policymakers, as well as financial markets, pay especially close attention to labor market indicators during periods of economic uncertainty. The reason, in short, is that changes in labor market activity are thought to be useful predictors for changes in real gross domestic product (GDP), the broadest measure of economic activity.

The main indicators of activity in the labor market include the civilian unemployment rate, nonfarm payroll employment, and average weekly hours, all of which are reported monthly in the Employment Situation from the Bureau of Labor Statistics (BLS). Indeed, the release of the monthly employment report seemingly rivals the post-FOMC meeting press release as the single most anticipated economic event in the financial markets. Given its significance, therefore, it is probably not too surprising that economists and market participants try to anticipate changes in this and other labor market indicators.

When it comes to forecasting monthly changes in the unemployment rate or the number of new nonfarm jobs created or destroyed, it appears that many economists and market participants pay particularly close attention to the report on initial unemployment insurance claims. This report, which is published by the Employment Training Administration (ETA), an agency within the U.S. Department of Labor, attempts to measure, on a weekly basis, labor flows from the ranks of the employed to the ranks of the unemployed (initial claims). The report also measures the total number of people currently unemployed who are eligible to receive unemployment insurance benefits (continuing claims).

William T. Gavin is a vice president and economist and Kevin L. Kliesen is an economist at the Federal Reserve Bank of St. Louis. The authors thank Cynthia Ambler of the Department of Labor for providing information on the unemployment insurance program. Rachel J. Mandal and Thomas A. Pollmann provided research assistance.

(C) 2002, The Federal Reserve Bank of St. Louis.
We begin with a brief review of the important monthly labor market data and their usefulness to economists, policymakers, and financial market participants. We then examine whether these labor market indicators are useful for predicting concurrent growth rates of real GDP. Finally, the paper will examine whether there is significant information to be gleaned from weekly changes in initial and continuing unemployment claims for predicting these monthly labor market indicators.

\section{LABOR MARKET DATA}

There are three major sources of data for the labor market: the household survey, the establishment survey, and the reports of state agencies that collect information about employment for the unemployment insurance program. The former two comprise the information that is found in the monthly employment report, while the latter is the source of information for the weekly unemployment insurance claims data.

\section{The Household Survey}

The household survey collects information from a small but representative sample of households. Currently, about 60,000 households are surveyed either in person or by telephone each month by the Bureau of Census. This survey, although it comprises less than 0.06 percent of the roughly 107 million households in the United States, is meant to be a representative sample of the U.S. civilian noninstitutional population, from which trends in labor market activity can be inferred. From that survey, known as the Current Population Survey (CPS), the BLS culls information on the demographics of the job market, such as race, age, sex, educational level, and detailed information about those who are unemployed, such as the duration of their unemployment.

The most important information from the CPS is the unemployment rate, which is plotted in Figure 1. Here, the monthly unemployment rates are averaged to get a quarterly rate. Since there is thought to be a significant cyclical relationship between changes in the unemployment rate and changes in aggregate output, also included is the four-quarter growth rate of GDP. ${ }^{1}$ Visual evidence

\footnotetext{
1 The relationship between real GDP growth and the unemployment rate is sometimes characterized by Okun's law. Named after the late economist Arthur Okun, the "law" says that for every percentage point that real GDP growth is above (below) its potential growth, the unemployment rate will fall (rise) by one-half a percentage point. See Mankiw (1998).
} 


\section{Figure 1}

\section{Unemployment Rate and Real GDP}

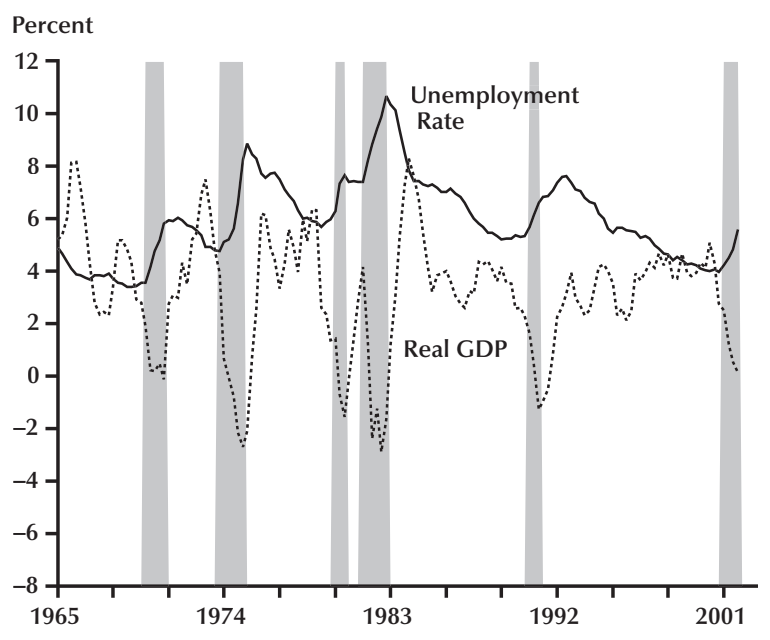

NOTE: The unemployment rate is a quarterly average of monthly rates. Real GDP is shown as a four-quarter growth rate. Bars indicate periods of recession.

suggests that, during recessions, the unemployment rate usually rises as real GDP declines. At other times, though, the relationship does not hold very well, suggesting that trends in the unemployment rate are not a reliable indicator of GDP growth. Indeed, as shown in Table 1, the correlation between the four-quarter growth of real GDP and the contemporaneous value of the unemployment rate is negative, but with a relatively low value $(-0.27)$. One reason why the two series might not be more closely correlated is that the unemployment rate lags the cycle. ${ }^{2}$

Another reason why changes in the underlying trend of the unemployment rate appear unrelated to the business cycle is the influence of microeconomic factors. These include changes in the benefits associated with being unemployed, changes in the demographics of the labor force, and cultural changes in family structure and work habits. Regarding the latter two factors, the large increase in the unemployment rate in the late 1960s and 1970s was associated with a growing number of young workers and women entering the labor force. And since the unemployment rates for young workers and women were higher than the average, this change in the composition of the labor force was associated with a rising trend in the unemployment rate. In the 1990s, as the baby boomers aged (fewer young people entering the labor force) and the labor force participation rate of women approached the rate of men, the unemployment rate has gradually declined.

\section{The Establishment Survey}

The establishment survey, also known as the Current Employment Statistics (CES) program, includes labor input information from about 350,000 nonagricultural establishments that employ about 39 million people. (Establishments are not the same as firms, but rather, they are distant parts of a firm in different locations. For example, the Federal Reserve Bank of St. Louis is a firm with establishments in St. Louis, Little Rock, Louisville, and Memphis.) The time series we use on payroll jobs and hours worked come from the CES. The data on employment growth from the CES are considered to be more accurate than the data from the CPS because the establishment survey has much greater coverage. Although the establishments surveyed are not representative, they nonetheless are the largest establishments and account for about 30 percent of the workforce (compared with 0.06 percent for the household survey). ${ }^{3}$

Figure 2 shows the four-quarter growth rate in jobs as well as the four-quarter growth rate in GDP. As can be seen visually in Figure 2, and statistically in Table 1, there is a much closer correlation between jobs growth and GDP growth than there is between the unemployment rate and GDP growth. The correlation between the four-quarter growth of real GDP and nonfarm payroll jobs is high, 0.79 . Here the cycles appear to coincide. However, there are sustained periods of productivity growth during which the economy grows faster than the work force. Most obvious in the chart are the decade of the 1960s and the five years following 1995. It appears that these periods of high productivity growth tend to occur during expansions.

The other major series that comes from the establishment survey is the index of hours worked. ${ }^{4}$

\footnotetext{
2 Further evidence of this assertion is that the average duration of unemployment is included in the Conference Board's list of lagging indicators. Its weight places it seventh out of seven in terms of its contribution to the index.

3 The results from this large sample are adjusted for the bias that exists between the composition of the approximately 350,000 large establishments surveyed and the composition of the roughly five million smaller establishments that are not included in the survey. This bias adjustment process, as it is known, is being replaced with a completely different methodology. See Getz (2000).

4 The index of aggregate hours worked is the product of average weekly hours and employment of production or nonsupervisory workers. See BLS Handbook of Methods.
} 


\section{Figure 2}

\section{Nonfarm Payroll Jobs and Real GDP}

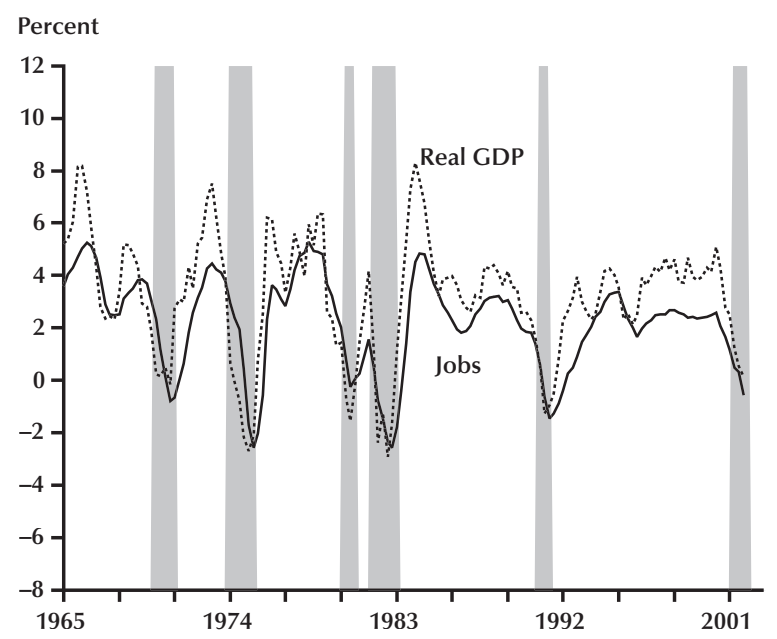

NOTE: Both payroll jobs and real GDP are shown as fourquarter growth rates. Bars indicate periods of recession.

\section{Figure 3}

\section{Nonfarm Hours Worked and Real GDP}

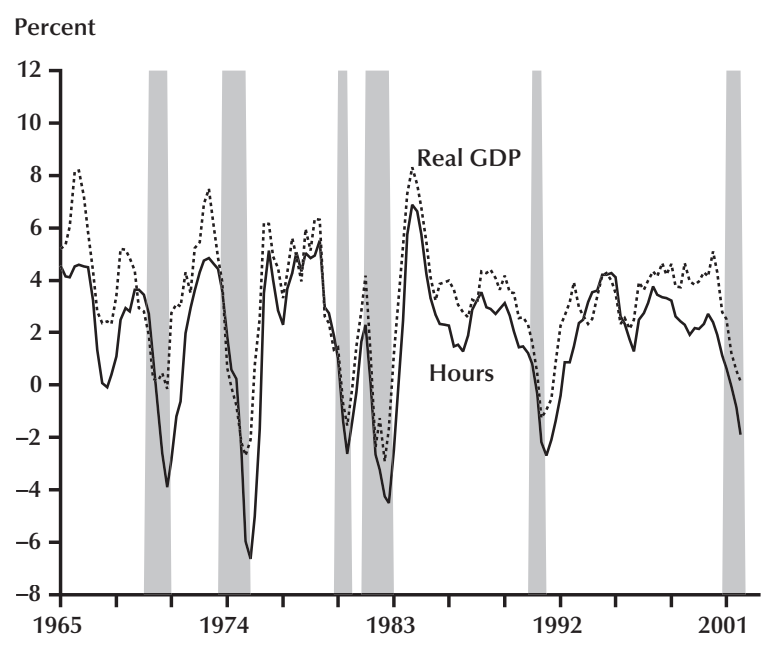

NOTE: Both hours worked and real GDP are shown as fourquarter growth rates. Bars indicate periods of recession.

\section{Table 1}

\section{Cross Correlations Between Real GDP Growth and Growth of Labor Market Variables}

\begin{tabular}{|c|c|c|c|c|c|c|}
\hline & $\begin{array}{c}\text { Continuing } \\
\text { claims }\end{array}$ & Real GDP & Hours & Initial claims & Jobs & $\begin{array}{c}\text { Unemployment } \\
\text { rate }\end{array}$ \\
\hline Continuing claims & 1 & -0.82 & -0.86 & 0.90 & -0.70 & 0.14 \\
\hline Real GDP & & 1 & 0.87 & -0.79 & 0.79 & -0.27 \\
\hline Hours & & & 1 & -0.69 & 0.94 & -0.37 \\
\hline Initial claims & & & & 1 & -0.50 & 0.05 \\
\hline Jobs & & & & & 1 & -0.48 \\
\hline
\end{tabular}

Unemployment rate

NOTE: Correlations of four-quarter growth rates except for the unemployment rate, which is in levels.

Figure 3 shows that growth in hours worked also moves closely with output growth over the business cycle. Indeed, among the labor variables cited earlier, the cross-correlations reported in Table 1 show that the growth of hours worked has the highest correlation with the growth of real GDP (0.87 over the sample period in Figure 3). Like jobs growth, the movement in the growth of aggregate hours is procyclical and appears to coincide with output growth.

One of the reasons why the monthly labor report from the establishment survey is considered so important is because it provides early information about GDP growth. To understand why this is so, note that a given month's report is released on the first Friday of the next month. For example, on the first Friday of each January, the Department of Labor will release information about the labor market in the previous December. The market will already have received labor market data for October and November. Labor data for the fourth quarter will be available in the first week of January, but the Department of Commerce will not release the advance estimate of fourth-quarter GDP growth until the last week of January. 


\section{Figure 4}

\section{Inital Claims and Real GDP}

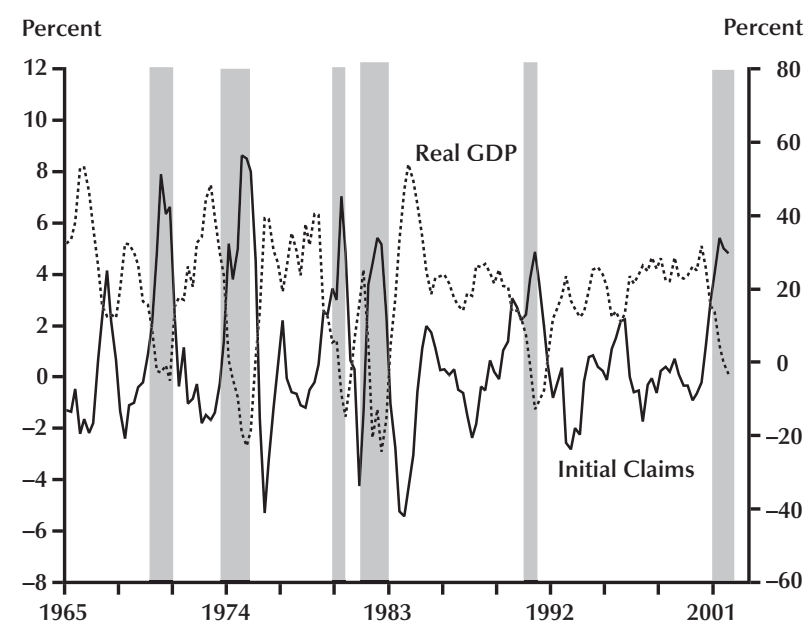

NOTE: Both initial claims and real GDP are shown as fourquarter growth rates. Bars indicate periods of recession.

The initial release of payroll jobs and hours worked is based on the establishment survey. According to the BLS, the most recent two months of estimates from the establishment data are considered preliminary because not all of the surveys have been returned and processed. Conceivably, then, the BLS may report up to three different estimates (current plus two subsequent revisions) of nonfarm job gains or losses for any month. But even these are still only preliminary, since the data on jobs and hours will be revised the following year with the annual benchmark revisions. The purpose of the benchmark revisions is to tie together the sample-based estimates that underpin the monthly establishment data with the actual "universe" counts of jobs, wages, and earnings that are reported to employment security agencies of the 50 states, the District of Columbia, Puerto Rico, and the Virgin Islands. Thus, the third source of information about the labor market is that reported to the Department of Labor by the state agencies that administer the federal-state unemployment insurance program.

\section{Covered Employment and Wages Program}

This program, also known as the ES-202 program, is a joint venture between the BLS and the state employment security agencies. The purpose of the

\section{Figure 5}

\section{Continuing Claims and Real GDP}

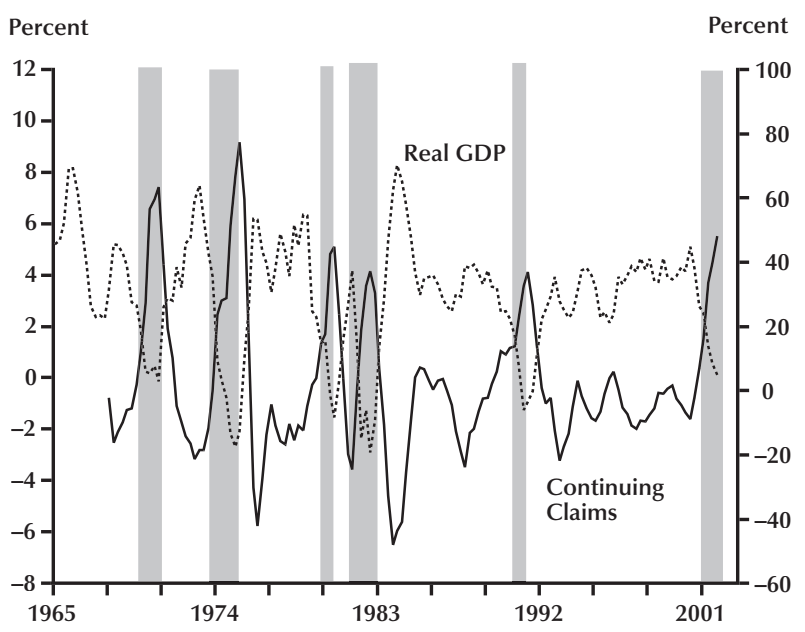

NOTE: Both continuing claims and real GDP are shown as fourquarter growth rates. Bars indicate periods of recession.

program is to provide a comprehensive accounting of nonagricultural employment and wage data by industry at the national, state, and local levels. Thus, coverage under the ES-202 program is nearly universal. In 1994, more than 96 percent of all wage and salary civilian jobs were covered by the ES-202 program, while covered employees accounted for nearly 93 percent of the wage and salary component of national income. Those excluded from the program coverage include agricultural workers, the military, and segments of state and local government employees.

This statewide information is aggregated to the national level by the ETA. Each week, the ETA releases statistics for the number of individuals filing new or continuing claims under the unemployment insurance (UI) program. The UI program is a joint arrangement between the federal government and individual state governments. Its purpose is to provide temporary unemployment benefits to eligible recipients. Though there are some common characteristics, each state operates under its own laws and, accordingly, sets program eligibility requirements. See the appendix for more detail on the program and its eligibility requirements.

Figure 4 shows the widely reported series, initial claims for unemployment insurance. Because growth in initial claims is much more variable than real GDP, their growth rates are shown on the right-hand 
scale in Figure 4. Initial claims are clearly countercyclical. Table 1 shows a high negative correlation between the four-quarter growth rates of the two series, -0.79 . Despite this high correlation, the National Bureau of Economic Research does not place much weight on initial claims when it comes to determining business cycle peaks and troughs. In a question-and-answer section in the on-line issue of The NBER's Recession Dating Procedure dated October 8, 2001, the following was posted:

Q: How do the movements of unemployment claims inform the Bureau's thinking?

A: A bulge in jobless claims would appear to forecast declining employment, but we don't use forecasts and the claims numbers have a lot of noise.

The weekly initial claims report also includes a series on those individuals that continue to draw unemployment compensation, otherwise known as continuing claims. Figure 5 shows the four-quarter growth of continuing claims and real GDP. Continuing claims are also much more variable than GDP, and their growth rates are shown in Figure 5 on the right-hand scale. Like initial claims, continuing claims are also countercyclical. Visually, it is difficult to distinguish the co-movement between initial and continuing claims, although growth of the latter appear to vary less. Either way, their correlations with GDP growth are virtually identical, as seen in Table 1.

\section{THE LABOR MARKET AND GDP}

From both a theoretical and empirical standpoint, the labor market is an important element in the economy. Output production requires combinations of labor, land, capital, and other factors. About two-thirds of the payments for factors go to the labor component. From the point of view of data collection, perhaps our best measure of economic activity is a measure of the number of people working.

As we saw in Figures 1 through 5, labor market indicators move in tandem with output over the business cycle. There is a considerable literature showing that monthly data in general, and labor data in particular, can be used to predict current quarter GDP. Miller and Chin (1996) survey this literature and report their own research showing that monthly information about hours worked helps predict GDP growth. Recently, Koenig, Dolmas, and Piger (2001) reported that monthly employment growth is a significant predictor of current-quarter GDP growth. Some private sector economists have even developed a "real time" model of aggregate economic activity that uses both initial and continuing claims to predict monthly changes in real GDP. ${ }^{5}$ Accordingly, monthly data should be able to predict quarterly GDP because the Bureau of Economic Analysis (BEA) uses monthly labor market data as an input to formulas that are used to estimate GDP components.

We evaluate the predictive content of monthly labor market data by adding these variables one at a time to a univariate autoregressive model of real GDP growth. We construct quarterly time series of incoming monthly labor market data. We forecast the current-quarter real GDP growth rate using incoming monthly labor market data from the same quarter. The general form of the forecasting model is

$$
y_{t}=c+\beta_{j} L M_{j, t}^{k}+\sum_{i=1}^{4} \delta_{i} y_{t-i}+\varepsilon_{t},
$$

where $y_{t}=\ln \left(G D P_{t} / G D P_{t-1}\right) \times 400$, the average annualized growth rate of GDP in the current quarter, and $L M_{j}^{k}$ is one of five labor market variables measured at the end of each of the three months in the quarter. The five labor market variables indexed by $k$ include the unemployment rate and the annualized growth rates of payroll jobs, aggregate hours worked, initial claims for unemployment insurance, and continuing claims for unemployment insurance. The labor market variable is indexed by $j$ to indicate which month of the current quarter is being used in the forecast. For example, at the end of the first month, $L M_{1, t}^{1}$ is the newly reported unemployment rate; at the end of the second month, $L M_{2, t}^{1}$ is the average of unemployment rates for the first two months of the quarter; and, at the end of the third month, $L M_{3, t}^{1}$ is the average of the three months of quarter $t$. Remember that the labor report for the third month of a quarter arrives three to four weeks before the first GDP report for that quarter. We consider each labor market variable separately. We also include four lags of GDP growth.

We use current vintage data in this forecasting experiment. ${ }^{6}$ In this experiment, we begin by estimating a model using data from 1967:Q2 through

\footnotetext{
5 See Hatzius (2001).

6 Koenig, Dolmas, and Piger (2001) have shown that it is possible to get a better forecast by using real-time vintage data. They show analytically that, if the revisions to data are not predictable, then the real-time vintage data will yield a forecast model with a smaller out-of-sample forecast error than one would get using current vintage data.
} 
1991:Q3. ${ }^{7}$ This model is then used to forecast the fourth quarter of 1991. We then update the forecasting model with 1991:Q4 data and use the newly estimated model to forecast the second quarter. That is, we update the model recursively and tabulate the forecasts through 2001:Q3. We then calculate the root-mean-squared error (RMSE) for that model forecast.

We examine six models. The first is simply the autoregressive (AR) component of the model excluding the labor market variable. The next five correspond to the labor market variables. The civilian unemployment rate is measured in level form, whereas the remaining four variables are measured as annualized growth rates. Note that in the case of these four variables, we calculate the first month's growth rate by taking the log ratio of the variable in the first month to the average of the three months in the previous quarter. In the second month we take the log of the ratio of the average of the first two months in the current quarter to the average of the three months in the previous quarter. In the third month we just look at the ratio of the three-month averages. In all cases involving variables in the GDP forecasting equation, we annualize growth rates.

To assess the statistical significance of the accuracy of the alternative model forecasts, we use two tests developed for nested forecasting models. In each case, we compare a model with lags of GDP growth and a labor market variable with a model that includes only lags of GDP growth. First, we use an out-of-sample F test of the null hypothesis that the model with the labor market variable has no predictive content for real GDP growth once the autoregressive model is taken into account. This test, developed by McCracken (1999), is given by

$$
\text { OOS-F }=P\left[\frac{M S E_{A R}-M S E_{L M^{k}}}{M S E_{L M^{k}}}\right],
$$

where OOS-F is the out-of-sample F test, $P$ is the number of forecasts made, $M S E_{A R}$ is the meansquared error for the AR model forecasts, and $M S E_{L M}$ is the mean-squared error for the models that include labor market variables. McCracken derives the limiting distribution of this test statistic under the null hypothesis and reports percentiles of the OOS-F statistic. He derives tables under alternative methods of updating the forecasting models. We use a recursive scheme. The critical values of the test statistic depend on which scheme is used and two other factors: (i) the number of labor market variables included (in each case we have one in each model) and (ii) the ratio $(P / R)$ of the number of forecasts $(P)$ to the number of observations used to estimate the model that was used to make the first forecast $(R)$.

Percentiles of the distribution are listed in the tables. We are comparing nested models so we use a onesided test. When the MSE of the forecasts from the unrestricted model is larger than the MSE from the restricted model, this test statistic is negative.

The second test we use is an out-of-sample test for encompassing. (Encompassing is simply that, if one forecast incorporates all of the relevant information, then adding information from the other forecast will not help predict the actual value.) We use an encompassing test of the null hypothesis that the AR model encompasses the model augmented with the labor market variable. This test, developed by Clark and McCracken (2000), is given by

$$
\mathrm{ENC}-\mathrm{CM}=P\left[\frac{M S E_{A R}-M C P E}{M S E_{L M^{k}}}\right],
$$

where ENC-CM is the encompassing test proposed by Clark and McCracken (2000) and MCPE is the mean cross product of the forecast errors from the restricted (AR) and unrestricted (LM) models. ${ }^{8}$ Clark and McCracken derive the limiting distribution of this test statistic under the null hypothesis and report percentiles of the ENC-CM statistic. As in the case of the OOS-F statistic, the limiting distribution depends on the method used to update the forecasting models, the number of parameters restricted to zero, and the ratio, $P / R$. The percentiles of the distribution are shown in Table 2. Again, we are comparing nested models, so we use a one-sided test. The statistic will be negative only if the average cross product is positive and larger than the meansquared error of the forecasts from the AR model.

The results of our evaluation are shown in Table 2. The first column reports results for the AR model (which excludes contemporaneous labor market data). This is the benchmark model and is nested in all the others. The RMSE of the forecast from the AR model for the period from 1990:Q1 to 2001:Q3 is 2.17 percent, with an adjusted $R^{2}$ of 6 percent for the last model estimated - that is, estimated over the period from 1967:Q2 to 2001:Q2.

\footnotetext{
7 Except in the case where the labor market variable is continuing claims. These data begin in January 1968.

8 The MCPE is calculated by the following formula:

$$
\frac{1}{T} \sum_{t=1}^{T} \hat{e}_{i t} \hat{e}_{j t}
$$
}




\section{Table 2}

\section{Evaluation of GDP Forecasts (1990:Q1 through 2001:Q3)}

\begin{tabular}{|c|c|c|c|c|c|c|}
\hline & $\begin{array}{l}\text { AR (4) } \\
\text { model }\end{array}$ & $\begin{array}{l}\text { Unemployment } \\
\text { rate }\end{array}$ & $\begin{array}{l}\text { Payrolls } \\
\text { jobs }\end{array}$ & $\begin{array}{c}\text { Hours } \\
\text { worked }\end{array}$ & $\begin{array}{l}\text { Initial } \\
\text { claims }\end{array}$ & $\begin{array}{c}\text { Continuing } \\
\text { claims }\end{array}$ \\
\hline \multicolumn{7}{|c|}{ RMSEs (out-of-sample forecasts) } \\
\hline First month & 2.17 & 2.17 & 1.81 & 1.95 & 2.18 & 2.23 \\
\hline Second & & 2.17 & 1.81 & 1.76 & 2.03 & 2.07 \\
\hline Third & & 2.17 & 1.78 & 1.66 & 1.93 & 1.93 \\
\hline Adjusted $\mathrm{R}^{2 *}$ & 0.06 & 0.06 & 0.57 & 0.63 & 0.41 & 0.47 \\
\hline \multicolumn{7}{|c|}{ McCracken out-of-sample $F$ test $^{\dagger}$} \\
\hline First month & & -0.31 & 20.32 & 10.75 & -0.40 & -2.64 \\
\hline Second & & -0.28 & 20.31 & 24.34 & 6.39 & 4.48 \\
\hline Third & & -0.28 & 22.29 & 32.65 & 12.48 & 12.25 \\
\hline \multicolumn{7}{|c|}{ Clark-McCracken nested encompassing test ${ }^{\ddagger}$} \\
\hline First month & & 0.11 & 26.75 & 24.42 & 6.38 & 6.44 \\
\hline Second & & 0.00 & 31.49 & 35.05 & 13.98 & 12.17 \\
\hline Third & & -0.07 & 34.60 & 39.86 & 20.65 & 17.87 \\
\hline \multicolumn{7}{|c|}{$\begin{array}{l}\text { NOTE: }{ }^{*} \text { Adjusted } \mathrm{R}^{2} \text { is for the full } 1967: \mathrm{Q} 1 \text { to } 2001: \mathrm{Q} 2 \text { sample using the } 3 \text {-month models. } \\
\text { †The null hypothesis is that the AR model is more accurate than the model with the labor market variable. Here } P / R=0.52 \text {. For } P / R=0.4 \text {, } \\
\text { the } 99 \text { th, } 95 \text { th, and } 90 \text { th percentiles for the OOS-F tests are } 2.768,1.298 \text {, and } 0.814 \text {, respectively; and for } P / R=0.6 \text {, the } 99 \text { th, } 95 \text { th, and } \\
\text { 90th percentiles for the OOS-F tests are } 3.719,1.554 \text {, and } 0.796 \text {, respectively. } \\
{ }^{\ddagger} \text { The null hypothesis is that the AR model encompasses the model with the labor market variable. Here } P / R=0.52 \text {. For } P / R=0.4 \text {, the } 99 \text { th, } \\
\text { 95th, and 90th percentiles for the Clark-McCracken encompassing tests are } 2.098,1.079 \text {, and } 0.685 \text {, respectively; and for } P / R=0.6 \text {, the } \\
\text { 99th, 95th, and 90th percentiles for the encompassing tests are } 2.662,1.312 \text {, and } 0.791 \text {, respectively. } \\
\text { Bold values indicate that the null hypothesis is rejected at the } 99 \text { th percentile. }\end{array}$} \\
\hline
\end{tabular}

The next column shows the results using the unemployment rate. As was suggested by Figure 1, changes in the unemployment rate since 1990 do not appear to help predict current-quarter real GDP growth. The explanatory power of unemployment was no better than with GDP alone, and the out-of sample forecasts were slightly worse, although the difference is small. The OOS-F statistics in the middle section of Table 2 are all negative, thus we cannot reject the hypothesis that the AR model is more accurate than the model that includes the unemployment rate. The same is true for the ENC-CM statistics. They are all below the 90th percentile value.

The next two columns show the models using growth in jobs and an index of hours worked. Here, there appears to be predictive information in the growth of payroll employment in all three months. Note, however, that the addition of the second month does not result in a lower RMSE for the model that includes payroll jobs. For the aggregate hours model, adding information from the second and third months lowers the RMSEs. These models also display a much higher in-sample explanatory power than does the model that includes the unemployment rate. For the models that include payroll jobs and hours worked, the OOS-F tests always reject the hypothesis that the AR model is more accurate. We can also reject the hypothesis that the AR model encompasses these models.

Finally, the two series using the unemployment insurance data lead to lower RMSEs only in the cases with two and three months of claims data included. Here the difference is large enough so that we can reject the null hypothesis that the AR model is more accurate than the models that include two or three months of claims (both initial and continuing). The RMSEs for the models that use initial or continuing claims from the first month only are generally higher than the RMSE from the AR model. The adjusted $R^{2}$ values for the models with three months of initial and continuing claims are 0.41 and 0.47 , respectively. Looking at the encompassing tests in the bottom 
section of Table 2, we see that we can reject the hypothesis that the AR model encompasses the model augmented with initial claims, even when the RMSEs are larger than the benchmark case.

In summary, we find that-consistent with previous empirical research-labor market data does help to predict GDP growth. In the next section, we examine the ability of weekly data on initial and continuing claims to predict the monthly time series on unemployment, payroll jobs, and the index of hours worked.

\section{PREDICTING MONTHLY LABOR MARKET DATA USING UNEMPLOYMENT INSURANCE DATA}

In the previous section we saw that initial and continuing claims for unemployment insurance are not very useful for predicting real GDP growth during the concurrent quarter. However, data on monthly employment and hours worked did help to predict GDP growth. Therefore, it would be useful to be able to predict employment and hours worked using the weekly claims data. Furthermore, many economists and financial analysts use weekly claims data to predict monthly changes in the unemployment rate. The payoff from this exercise is potentially quite large, since unexpected changes in the unemployment rate can be a significant market mover; moreover, these changes can sometimes induce immediate changes in monetary policy. ${ }^{9} \mathrm{~A}$ typical example of the analysis that posits a causality between unemployment insurance claims and the unemployment rate may be found in the following Monetary Policy Report to the Congress:

Employment continued to decline in December and January but much less than in the preceding two months. Manufacturing and its related industries lost jobs at a slower pace, and employment leveled off in other private industries. The unemployment rate moved up to 5.8 percent in December but then ticked down to 5.6 percent in January. The recent reversal of the October and November spikes in new claims for unemployment insurance and in the level of insured unemployment also point to some improvement in labor market conditions early this year. (Board of Governors of the Federal Reserve System, February 2002, p. 20)
A recent study by Montgomery et al. (1998) uses monthly initial claims data to forecast the quarterly unemployment rate. The study finds some support for the predictive content of monthly initial claims. ${ }^{10}$ The contribution of initial claims was concentrated in periods when unemployment was rising. McConnell (1998) reports a similar finding in which she uses initial claims data to forecast payroll jobs growth. In her study, initial claims helped to predict payroll jobs, but only during periods of recession. In this study we are looking at the ability of the weekly data to predict the monthly series: not only the unemployment rate, but the jobs and hours worked data as well.

We use a model analogous to equation (1) to evaluate the ability of the unemployment insurance claims data to predict the monthly labor statistics:

$$
L M_{t}^{k}=c+\beta_{j} \text { Weekly } y_{j, t}^{a}+\sum_{i=1}^{12} \delta_{i} L M_{t-i}^{k}+\varepsilon_{t},
$$

where the dependent variable is one of three monthly labor market series: the unemployment rate, growth in payroll jobs, and growth in the index of hours worked. Here, the growth rates are monthly. There are two alternative weekly series used on the right-hand side of equation (2): initial claims and continuing claims. The data on initial claims are released on Thursdays and apply to the previous week that ended five days earlier. The data on continuing claims released at the same time apply to the week that ended 12 days earlier.

We create five monthly series from each of these latter two data series, initial and continuing claims. The first weekly series is the data reported on the first Thursday following the first Friday of the month, the normal release date for the Employment Situation. We take the logarithm of the ratio of this weekly release to the average for the previous month. The second weekly series is the logarithm of the ratio of the average data reported on the first and second Thursdays (following the first Friday of the month) to the previous month's average, and so forth. We do not create a fifth series because there is not always a fifth Thursday. Instead, we create a series that we call the last week, which includes the

\footnotetext{
9 See Jordan (1992).

10 They started with seasonally adjusted data, but as usual in these time-series models, they had to include the seasonal terms to get rid of the residual correlation. We briefly examined ARIMA and Bayesian VAR methods, but, overall, none generate more accurate forecasts than the univariate regressions reported herein.
} 


\section{Table 3}

\section{Regression Output for Period from February 1968 to November 2001}

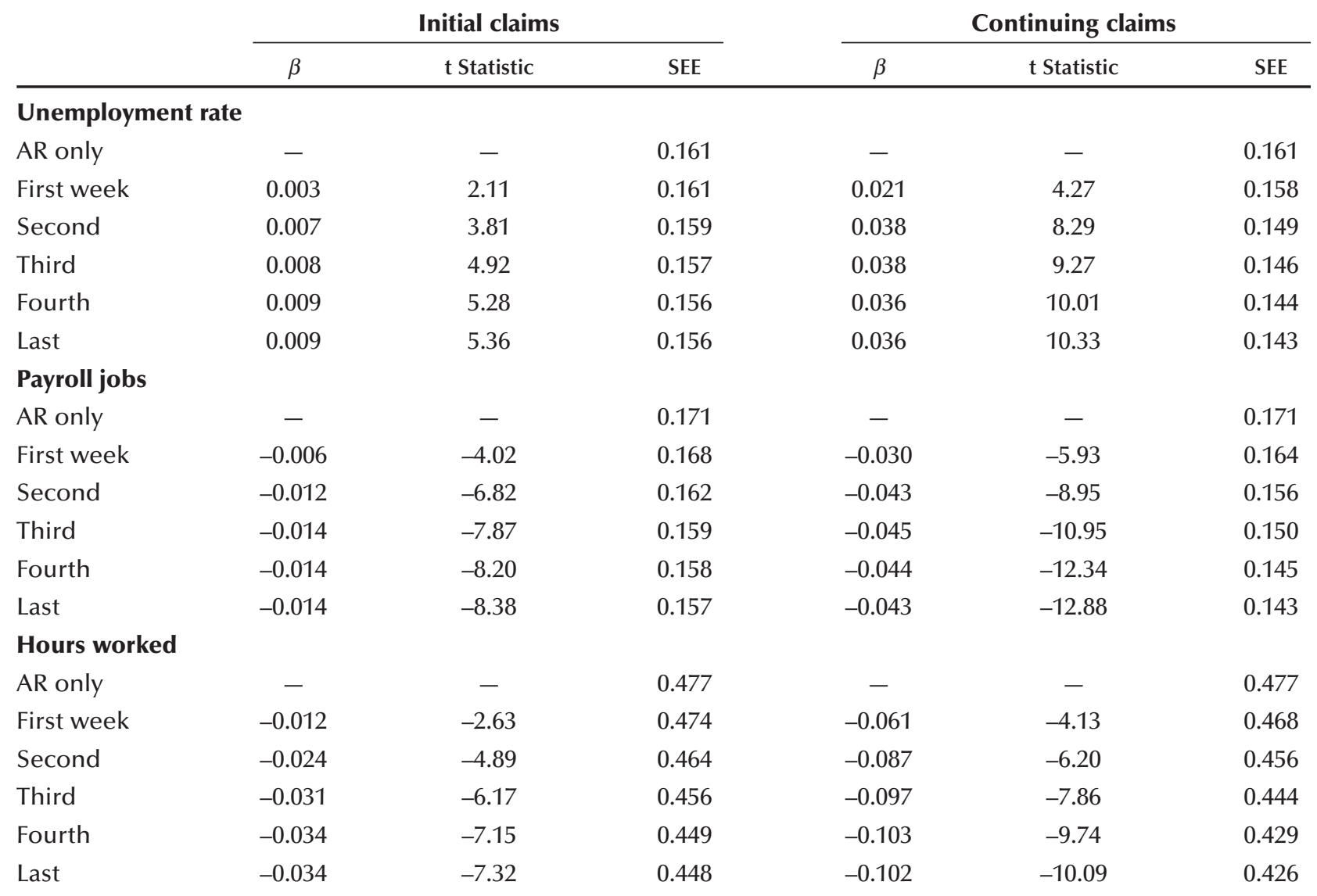

NOTE: The values in the table are estimates of $\beta_{j}$, its t statistic, and the standard error for equation (2).

average of the data released in the first four weeks when there is no fifth week available.

The estimation results for the weekly initial claims models using the full data set are shown in Table 3. The estimation period includes the months from February 1968 through November 2001. We estimated OLS models for the three labor market variables. Each model included a constant and 12 lags of the dependent variable as well as our weekly series that use information about unemployment insurance claims. There are three sections in Table 3. The top section shows the results for the unemployment rate. The first row reports the standard error of the equation (SEE) for the autoregressive (AR) model which excludes the claims data. The estimate of the coefficient on the weekly initial claims data is reported in the first column of results with the $t$ statistic for that coefficient reported in the second column. The third column reports the SEE for the equation. The last three columns report the analogous results for continuing claims. The middle section includes the results for payroll jobs, and the bottom section reports the results for hours worked. Overall, the in-sample fit improved with the accumulation of information throughout the month. Uniformly, the data on continuing claims do a better job of predicting the labor market variables than do the initial claims data. This condition is true in spite of the extra-week delay in reporting information about continuing claims.

\section{An Out-of-Sample Forecasting Exercise}

To evaluate the predictive content of the claims data, we conduct an out-of-sample forecasting 


\section{Table 4}

Evaluation of Monthly Forecasts of Labor Market Indicators (Current Month Forecasts from January 1990 to November 2001)

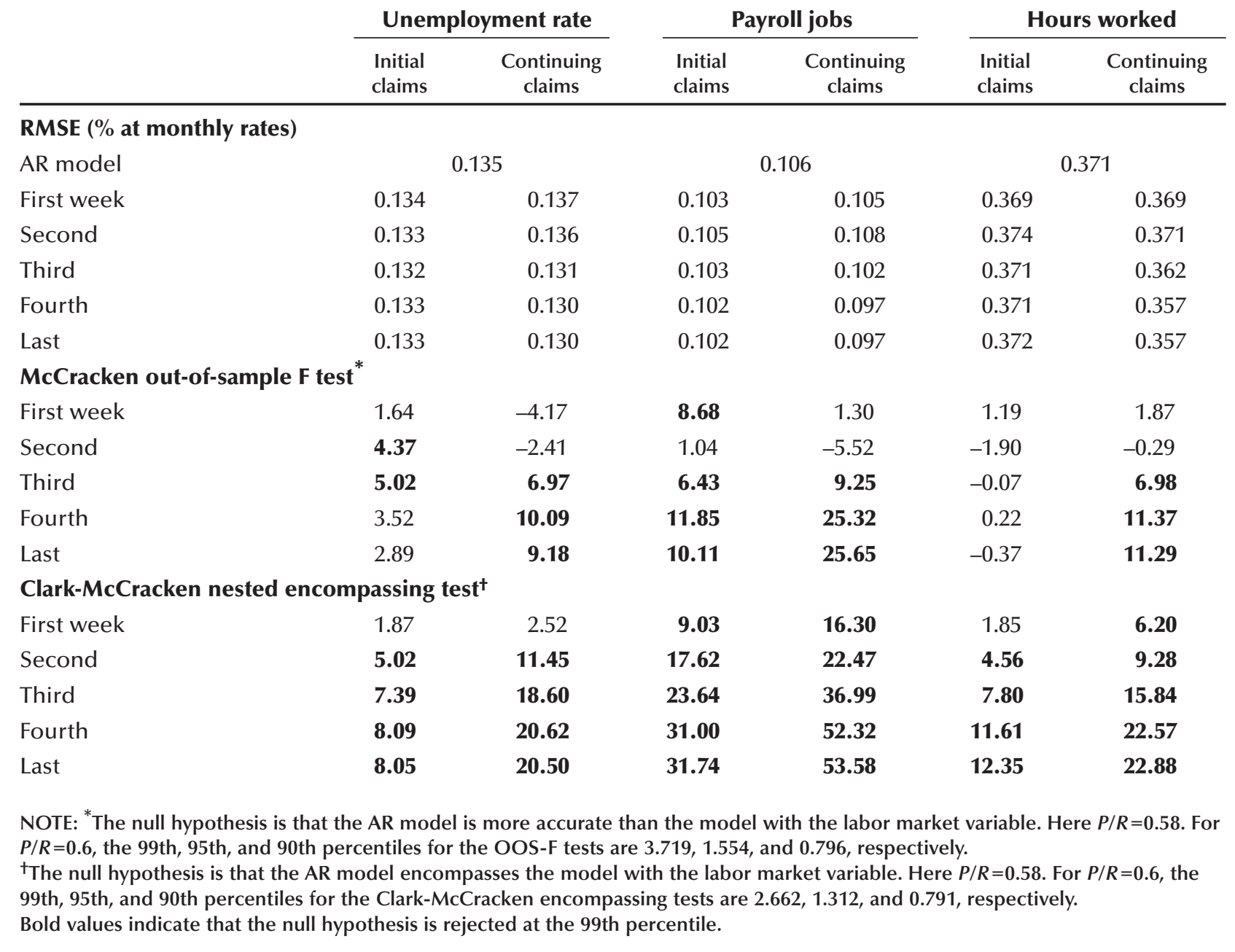

experiment. Again, we are using current vintage data to construct these out-of-sample forecasts. We begin by estimating the model over the period from February 1968 through December 1989. As before, we update the model each month before we make the next forecast, recursively computing the forecasts through November 2001. The RMSEs of the forecasts are reported in the top section of Table 4. The first row of results include the RMSEs from the forecasts made by the autoregressive models. Here the sample period includes the months from January 1990 through November 2001.

The out-of-sample forecasting results are not entirely consistent with the in-sample fit where continuing claims always outperformed initial claims. Here, initial claims appears to do a better job forecasting the unemployment rate and payroll job growth early in the month and continuing claims does better late in the month. In the second and third sections of Table 4, we report the out-of-sample tests for equality of MSEs and encompassing, respectively. Again, we compare the forecasts from the full model with forecasts from the AR model that is nested within each of the full models. Therefore, we use the tests for nested models that were described above. The forecasting method was recursive, there is one restriction on the AR model, and the $P / R$ ratio for this experiment is 0.58 , so we use the percentiles for $P I R=0.6$ where the 99th percentile for the OOS-F test statistic is 3.719. 


\section{Table 5}

Evaluation of Monthly Forecasts of Labor Market Indicators (Current Month Forecasts from April 1991 to February 2001-Expansion Months Only)

\begin{tabular}{|c|c|c|c|c|c|c|}
\hline & \multicolumn{2}{|c|}{ Unemployment rate } & \multicolumn{2}{|c|}{ Payroll jobs } & \multicolumn{2}{|c|}{ Hours worked } \\
\hline & $\begin{array}{l}\text { Initial } \\
\text { claims }\end{array}$ & $\begin{array}{l}\text { Continuing } \\
\text { claims }\end{array}$ & $\begin{array}{l}\text { Initial } \\
\text { claims }\end{array}$ & $\begin{array}{c}\text { Continuing } \\
\text { claims }\end{array}$ & $\begin{array}{l}\text { Initial } \\
\text { claims }\end{array}$ & $\begin{array}{c}\text { Continuing } \\
\text { claims }\end{array}$ \\
\hline \multicolumn{7}{|c|}{ RMSE (\% at monthly rates) } \\
\hline AR (12) model & \multicolumn{2}{|c|}{0.128} & \multicolumn{2}{|c|}{0.095} & \multicolumn{2}{|c|}{0.374} \\
\hline First week & 0.127 & 0.132 & 0.092 & 0.097 & 0.371 & 0.373 \\
\hline Second & 0.126 & 0.133 & 0.097 & 0.103 & 0.375 & 0.379 \\
\hline Third & 0.126 & 0.128 & 0.097 & 0.100 & 0.374 & 0.375 \\
\hline Fourth & 0.127 & 0.128 & 0.097 & 0.095 & 0.373 & 0.369 \\
\hline Last & 0.128 & 0.129 & 0.097 & 0.094 & 0.373 & 0.369 \\
\hline \multicolumn{7}{|c|}{ McCracken out-of-sample F test ${ }^{*}$} \\
\hline First week & 1.13 & -6.95 & 6.82 & -6.05 & 1.93 & 0.70 \\
\hline Second & 3.04 & -8.64 & -5.82 & -19.20 & -0.63 & -3.49 \\
\hline Third & 3.24 & -1.29 & -4.88 & -11.43 & 0.06 & -0.89 \\
\hline Fourth & 0.56 & -0.93 & -4.64 & -0.50 & 0.13 & 3.32 \\
\hline Last & 0.19 & -1.84 & -6.05 & 0.76 & 0.13 & 3.18 \\
\hline \multicolumn{7}{|c|}{ Clark-McCracken nested encompassing test ${ }^{\dagger}$} \\
\hline First week & 2.08 & 1.25 & -8.31 & -5.94 & 1.71 & 3.93 \\
\hline Second & 5.86 & 8.69 & 0.24 & -0.55 & 3.54 & 6.11 \\
\hline Third & 7.37 & 13.60 & 4.20 & 8.14 & 6.04 & 10.05 \\
\hline Fourth & 7.94 & 14.37 & 9.12 & 17.05 & 9.28 & 15.05 \\
\hline Last & 7.92 & 14.26 & 9.25 & 18.96 & 9.80 & 15.12 \\
\hline
\end{tabular}

Using a 1 percent critical region, the $\mathrm{F}$ tests reject the null hypothesis that the AR forecast of the unemployment rate is better than the initial claims forecast for the second and third weeks, but not for the fourth and last weeks. This hypothesis is rejected for the continuing claims data in the models where at least three weeks of data are available. We can reject the null hypothesis for payroll jobs as well, when we can use initial claims data for all but the model with the first two weeks of data. As we found with the unemployment rate, the null hypothesis is rejected in the cases using at least three weeks of continuing claims data. We cannot reject the null hypothesis in the case of hours worked for initial claims, but we can for cases including three or more weeks of continuing claims data. The encompassing tests are reported in the bottom panel of Table 4. In all but a few cases involving models with just the first-week data, we can reject the null hypothesis that the AR model encompasses the models including the claims variables at the 99th percentile.

Our forecasting period included the recession that began in July 1990 and ended in March 1991, as well as the first nine months of the current recession. Both Montegomery et al. (1998) and McConnell (1998) conclude that initial claims data can forecast labor market variables, but only in times of recession and rising unemployment. Therefore we calculated the forecasting performance of these models during the 10 years of expansion from April 1991 through 
February 2001. These results are reported in Table 5 . Looking at expansion months only, we find much less information in the claims data. However, there is still some evidence that initial claims data help to predict the unemployment rate and continuing claims data help to predict growth in hours worked. Again, even though the AR model often had a lower RMSE, we could always reject the hypothesis that the AR model encompassed the model that included the claims data when we used at least three weeks of data.

\section{CONCLUSION}

Empirical evidence and economic theory suggest that changes in labor market conditions will have significant effects on aggregate output. Evidence presented in this paper further suggests that incoming monthly data on nonagricultural payroll jobs and the index of aggregate weekly hours help predict changes in real GDP growth. Changes in the civilian unemployment rate are less significant. This finding suggests that predicting monthly changes in jobs or hours growth would be helpful in predicting real GDP growth. Many economists and financial market analysts strive to do this by tracking initial claims for state unemployment insurance benefits, which are released weekly. This article has shown that there is some statistically significant marginal information in the unemployment insurance claims data, even during periods of expansion. However, information about continuing claims appears to be at least as important as the information about initial claims that usually appears in the headlines.

\section{REFERENCES}

Board of Governors of the Federal Reserve System.

Monetary Policy Report to the Congress. February 2002.

Clark, Todd E. and McCracken, Michael W. "Tests of Equal Forecast Accuracy and Encompassing for Nested Models.”
Working Paper RWP 99-11, Federal Reserve Bank of Kansas City, November 2000.

Getz, Patricia M. "Implementing the New Sample Design for the Current Employment Statistics Survey." Business Economics, October 2000, 35(4), pp. 47-50.

Hatzius, Jan. "Jobless Claims Imply Contraction, but Only at a Glacial Pace." Goldman Sachs Economics Goldman U.S. Daily, 15 June 2001.

Jordan, Jerry L. "What Monetary Policy Can and Cannot Do." Federal Reserve Bank of Cleveland Economic Commentary, 15 May 1992.

Koenig, Evan F.; Dolmas, Sheila and Piger, Jeremy M. "The Use and Abuse of 'Real-Time' Data in Economic Forecasting." Working Paper 2001-015A, Federal Reserve Bank of Dallas, 2001.

Mankiw, N. Gregory. Principles of Economics. Orlando, FL: Harcourt Brace, 1998.

McConnell, Margaret M. "Rethinking the Value of Initial Claims as a Forecasting Tool." Federal Reserve Bank of New York Current Issues in Economics and Finance, November 1998, 4(11), pp. 1-6.

McCracken, Michael W. "Asymptotics for Out of Sample Tests of Causality.” Unpublished manuscript, Louisiana State University, November 1999

Miller, Preston J. and Chin, Daniel M. "Using Monthly Data to Improve Quarterly Model Forecasts.” Federal Reserve Bank of Minneapolis Quarterly Review, Spring 1996, 20(2), pp. 16-33.

Montgomery, Alan L.; Zarnowitz, Victor; Tsay, Ruey S. and Tiao, George C. "Forecasting the U.S. Unemployment Rate." Journal of the American Statistical Association, June 1998, 93(442), pp. 478-93. 


\section{Appendix}

\section{METHODOLOGY OF THE UNEMPLOYMENT INSURANCE CLAIMS DATA}

\section{Data Series and Sources}

Each week, state government employment offices report the number of individuals filing claims for unemployment insurance benefits. The state offices then report the figures to the Office of Workforce Security in the ETA. ${ }^{11}$ They are then published in the Unemployment Insurance Weekly Claims Report, which is issued by the ETA. Also published in this report are continuing claims for state unemployment insurance benefits (insured unemployment), which is another closely monitored indicator.

\section{Eligibility Requirements}

Individuals who file for unemployment insurance benefits are not automatically eligible for benefits. To qualify for benefits, the worker must first demonstrate that they have a work history, otherwise known as an "attachment to the labor force." In most states, this requirement is met by having earned a minimum amount of money in a job that is covered by the law. In some states, a person is eligible if they have merely worked a minimum amount of time in covered employment. Covered employment excludes self employment, small farms, and small domestic operations. Once the person is deemed monetarily eligible, the reason for the claim is then examined. Although a common reason stems from an unintended loss of employment, some states disburse benefits to individuals who are following a spouse to a new job. If an unfavorable ruling results, the claimant may appeal the decision.

\section{Waiting Period Requirements}

In general, individuals do not receive benefit checks for two to three weeks after they are classi- fied as eligible. Moreover, there is an additional lag in those states that have a one-week waiting period. This means that they cannot claim benefits for that week. Most states require that claimants file for benefits every two weeks. For every week a person claims benefits, they are required to be available and actively seeking work, and, among other things, they cannot refuse a suitable job.

\section{Type of Claims}

The initial claims series that is reported weekly comprises two types of claims: new and additional. A new claim is defined as the first initial claim filed in person, by mail, telephone, or other means to request a determination of entitlement to and eligibility for compensation. This results in an agencygenerated document to determine monetary eligibility. An additional claim is a subsequent initial claim filed (i) during an existing benefit year due to new unemployment and (ii) when a break of one week or more has occurred in the claim series due to intervening employment. Thus, these claims are reported only when there has been intervening employment since the last claim was filed. Claims that follow breaks due to illness, disqualification, unavailability, or failure to report for any reason other than job attachment are not reported. Thus, if a person has multiple occurrences of unemployment during their benefit year, the first one is counted as a new initial and the others are counted as additional initials. Both numbers are incorporated into the published weekly counts and thus represent new emerging unemployment for that week.

\footnotetext{
11 The claims data are not derived from the ES-202 program, which is the source of employment and wage data by industry at the national, state, and county levels. Thus, they are not drawn from the sample of data that is used to construct the establishment data in the monthly Employment Situation report, nor are they used to calculate the unemployment rate, which comes from the household survey.
} 
